\title{
Situación Social de la Poesía \\ de Rubén Darío
}

POr WASHINGTON DELGADO.

Al cumplirse, casi al mismo tiempo, dos aniversarios de Rubén Darío, el cincuentenario de su muerte y el centenario de su nacimiento, su obra y su vida cobran un relieve históri co que ha de permitir, sin duda, apreciarlas nítida e imparcialmente. La crítica literaria, en general, ha señalado ya, no sólo el valor estético y singular de la poesía rubendariana, sino también su importancia histórica en América y en España. En es tos momentos casi pareceilobxioadlecietquae Rubén Darío es, por lo menos cronológicameniése ellcpipeltifieregran poeta americano, y también el restaurador de la postrada poesía española del siglo XIX. Poeta verdadero, audaz, profundo y original, nacido en tierras americanas, Rubén Darío no es un imitador ni copista de poetas españoles a la moda; no se limita como sus antecesores continentales a expresarse según las reglas de una retórica - tradicional o novedosa - importada de la madre patria. Rubén Darío, además, surge en el ámbito de la lengua castellana en un momento crítico de la poesía: nunca en España se había llevado el verso a regiones de tan extremado prosaís mo como en la época de López de Ayala, Núñez de Arce, Campoamor y Bartrina; las sonoridades mismas del viejo octosílabo y del endecasílabo al itálico modo se muestran apagadas, casi totalmente, o cambiadas en un sonsonete sin melodía ni sen tido. Del hasta entonces mudo hemisferio occidental llega $\mathrm{Ru}^{-}$ bén Darío, con su poesía maravillosamente melodiosa e inicia la renovación del lenguaje poético; renovación que constituye la base de un renacimiento literario español -el de la generación del 98 y las que le sucedieron- que con razón puede parangonarse al Siglo de Oro. 
Aparte de un puro juicio estético, de una crítica exclusivamente literaria, el valor histórico de la poesía de Rubén Darío tiene una capital importancia: se le puede considerar, en justicia, el precursor de la actual poesía en lengua castellana. No faltan, sin embargo, las voces discordantes y acaso la más excelsa sea la de Luis Cernuda, el gran poeta andaluz muerto recientemente, quien en la reseña crítica de un estudio de Bowra, le niega toda vigencia a la obra de Darío y afirma que su poesía está muerta definitivamente, que su influencia en los poetas de hoy es nula. Si bien Cernuda no deja de tener razón cuando afirma que los poetas ya no leen a Rubén Darío como a un maestro ni son influídos por su poesía, no deja de ser cierto asimismo, que los maestros de los poetas de hoy - Juan Ramón Jiménez, Antonio Machado, Salinas, Guillén, Vallejo, Neruda- sí estuvieron bajo la influencia rubendariana, influencia que, al menos de este modo mediato, indirecto, llega hasta nuestros dias. Para justipreciar esta influencia, para juzgar la obra misma de Darío, nos parece necesario, imprescindible, situarla históricamente; esa obra - que tuvo tal resonan: cia en su época- no puede ser separada del mundo en que vivió.

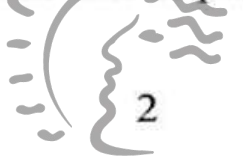

La poesía de RubémlDaxíodplantea una serie de preguntas inquietantes. Un poetaJ tan originłal,vestan refinada técnica versificatoria ¿cómo pudo aparecer en un pequeño país americano sin mayor tradición literaria? ¿Por qué su poesía produjo tal conmoción y fervor en América? ¿Por qué esa poesía tuvo semejante influencia en España? No se pueden contestar estas preguntas hablando simplemente del genio, de su carácter singular y azaroso, de su potencia misteriosa e inexplicable. De hecho, alrededor de Darío surgió inmediatamente una pléyade admirable de poetas: la escuela modernista; escuela que tampoco puede ser considerada un simple evento literario, que es más bien una cima de la evolución cultural americana en el siglo pasado.

La literatura americana en lengua española aparece y se desarrolla durante la colonia; es, naturalmente, una literatura colonial: mera imitación, copia o calco de la española; limitada a seguir apagadamente y a la distancia, los vaivenes de la moda literaria peninsular: culterana cuando en España ha triunfado Góngora; o neoclásica, cuando se han impuesto en España las normas y preceptos franceses. Producida la independencia se 
rompieron los vínculos coloniales en la politica y en la economía; pero se mantuvieron los vinculos literarios. Desaparecido el monopolio comercial y el administrativo, los escritores americanos continuaron unidos apendicularmente a la literatura es pañola. En todo caso, y como España en los siglos XVIII y XIX, había perdido su fuerza creadora artística, y sus poctas imitaban, con mayor o menor fortuna a los poetas europeos, los escritores americanos se dedicaron a imitar esas imitaciones. América viene a ser el espejo de un espejo, un vasto continente donde se producía una literatura de tercera mano, sin calidad alguna. Algunos escritores, ciertamente, leyeron libros franceses, ingleses, italianos, y aun alemanes, en su idioma original, y escribieron bajo esa influencia inmediata: son las excepciones que confirman la regla. La literatura española durante los primeros años de vida independiente es el modelo principal; $y$, de todos modos, en el caso de las excepciones más notables, no hay originalidad apreciable; la regla sigue siendo la imitación: si no de la española, de otra literatura europea. Todavía en 1910 Riva Agüero decía que la literatura americana no podía ser original, que debía seguir las corrientes literarias inventadas en Europa, y que solamente podía aspirar a cierto grado de peculiaridad, que en la práctica, por lódemás, no alcanzaba a menudo. Como si aún vivieran en la Colonia, los escritores americanos se encasillan en la litteratura triunfante en la metrópoli

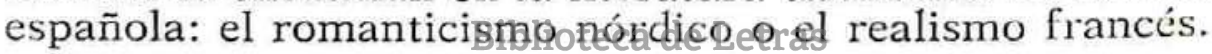

\section{"Jorge Puccinelli Converso"}

Tal situación cambia justamente con la aparición del modernismo y Rubén Darío es el primer poeta americano que no se limita a copiar los temas, motivos y procedimientos imperantes en España. Por el contrario su obra poética es acogida con entusiasmo en la Península y prontamente aparecen en ella sus epígonos e imitadores. En el caso del modernismo, España es quien importa una escuela literaria nacida en tierras americanas; y la escuela modernista, en cierta medida es un producto originalmente americano; no hay un modernismo francés, alemán o inglés.

No se puede decir sin embargo, que la poesía modernista posea una absoluta originalidad americana. Aunque no se trata de la imitación directa de un inexistente modernismo europeo, la influencia europea es clara y evidente; el modernismo americano es una curiosa síntesis de varias escuelas literarias francesas: romanticismo, parnasianismo, simbolismo, realismo y naturalismo. Es importante y sugestivo el estudio de los motivos y procedimientos que pasan de cada una de las escuelas 
mencionadas al modernismo, y de la medida en que son asimilados y transformados; pero acaso sea más revelador, comprobai simplemente cómo escuelas tan diversas y aun opuestas, se unen en el crisol modernista. La amplitud de la síntesis tiene más importancia de lo que a simple vista pueda creerse. Es en realidad una característica esencial del modernismo.

Hay dos notas en la poesía de Rubén Darío: el cosmopolitismo y la fe en la belleza, que bien pueden considerarse como las dos constantes fundamentales de su vida y de su obra. Rubén Dario es un poeta cosmopolita de patria plural o múltiple: Nicaragua, su patria original; Chile su segunda patria; Argentina su segunda patria de encanto; España, su patria madre: Francia, su patria universal. Pedro Salinas ha señalado acertadamente, cómo esta multiplicidad de patrias no significa que Darío fuera un frívolo viajero, un internacionalista vacuo; su cosmopolitismo es el resultado de una fina actitud espiritual. "Yo soy - ha dicho él missmo- de la raza en que se usa el yelmo del Manchego y el penacho del Gascón. Yo soy del país en que un grupo de ancianos se sientan, cerca de las puertas Sceas a celebrar la hermosuyaj de Etelena con una voz "lilial" como dice Homero; yo soy derdos paásesnpindáricos en donde hay vino viejo y cantos nuevos. Yo soy de Grecia, de Italia, de Francia, de España". La patria múltiple de Rubén Darío no es un territorio geográfico, es una creación íntima y poética, producto de muchos amores y mezcla de variadas esencias culturales.

El cosmopolitismo de Rubén Darío obedece a un ideal profundo del que brotan varias características de su poesia. En primer lugar el nomadismo; Darío es un viajero precoz e impenitente: en plena adolescencia, a los quince años, inicia su peregrinaje, por tierras americanas primero -Centroamérica, Chile, la Argentina-y por la soñada Europa después. En su poema del retorno a la tierra natal lo declara así:

Por atavismo griego o por fenicia influencia, siempre he sentido en mí ansia de navegar y Jasón me ha legado su sublime experiencia y sentir en mi vida los misterios del mar

(Retorno, en POEMA DEL OTOÑO Y OTROS POEMAS). 
Este nomadismo, de profundas raíces espirituales es el resultado de un idealismo cosmopolita. Su poesía rebosa un ansia ecuménica, universalizadora, una gana permanente de reunir bajo la luz del arte multitud de paisajes y recuerdos, de tiempos y lugares, de flores y animales, de gentes y culturas. En poemas como Divagación o Pórtico (escrito para el libro "En tropel" de Salvador Rueda) aparece como motivo dominante su cosmopolitismo; en estos poemas desfilan tumultuosa y rítmicamente gran copia de países y épocas: Grecia y los mármoles de Paros, el cielo azul de Lacio, la Arabia feliz, el Oriente morisco, la errante familia bohemia, España fresca y riente y sobre todo Francia porque Francia encarna el sueño cosmopolita del poeta: "Amo - dice en Divagación-, amo más que la Grecia de los griegos la Grecia de la Francia".

El exotismo de la poesía de Rubén Darío no es superficial ni postizo, tiene hondas motivaciones sicológicas e ideales. Todo el acopio de elementos culturales, diversos y dispuestos en un orden aparentemente arbitrario, constituye una de las claves más importantes de la poesía rubendariana. Cuando Rubén Darío agobiado por el sufrimiento y el infortunio, retorna a su Nicaragua natal, no encuentra nada mejor para expresar su sentimiento que esta exclámación llena de menciones exóticas:

En el lugar en donđe luve la luz y el bien

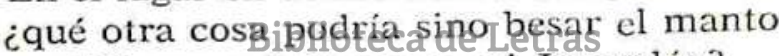
a mi Roma, mibitenasegi miivescusalén?

(Retorno, en POEMA DEL OTONO Y OTROS POEMAS).

Toda el alma de Rubén Darío está en estos versos.

La fe en la belleza es la segunda nota distintiva de la poesía de Rubén Darío, de todo el modernismo. Esta fe es el resultado de un idealismo íntimo e intenso. Rubén Darío y los poetas americanos de su generación o de su escuela, son unos platonistas irremediables; a pesar del aparente materialismo sensorial de sus imágenes, más que sensuales son -para usar palabras del propio Darío- sentimentales, sensibles y sensitivos; y lo son en tal grado que perciben las esencias más escondidas de la naturaleza, el alma secreta de cada objeto:

...Las cosas tienen un ser vital; las cosas tienen raros aspetos, miradas misteriosas; toda forma es un gesto, una cifra, un enigma; 
en cada átomo existe un incógnito estigma;

cada hoja de cada árbol canta un propio cantar

y hay un alma en cada una de las gotas del mar;

el vate, el sacerdote, suele oir el acento

desconocido...

(Coloquio de los Centauros, en PROSAS PROFANAS).

Cada ser del universo posee un alma íntima que a veces el poeta vislumbra; pero esas almas son fragmentos de la luz ideal de la belleza, alma suprema de las cosas del mundo:

Sobre su altar de oro se levanta la Dea

-tal en su aspecto icónico la virgen bizantina-:

toda belleza humana ante su luz es fea;

toda visión humana a su luz es divina:

y esta es la virtud sacra de la divina idea

cuya alma es una sombra que todo lo ilumina.

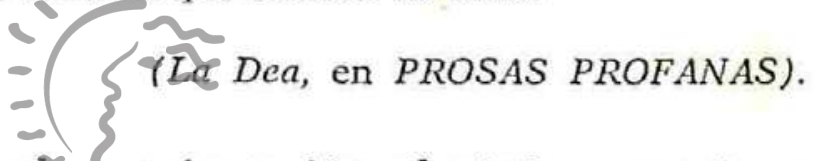

Estos versos tienen una clara orientación platónica común a todo el modernismo; talbplateonismnottiene un corolario: la creencia de que la función deglappóesía es justamente encarnar en la palabra la belleza ideal. Dirigiéndose al cisne - ave emblemática de la belleza perfecta- dice Rubén Darío:

Bajo tus blancas alas la nueva Poesía concibe en una gloria de luz y de armonía la Helena eterna y pura que encarna el Ideal.

(El Cisne, en PROSAS PROFANAS).

En otros poemas - La Fuente, Palabras de la Satiresa, Ama tu ritmo - se repite esta concepción de la poesía como reveladora de la belleza ideal y suprema. El poeta debe saber que "el secreto de todo ritmo y pauta está en reunir carne y alma a la esfera que gira" (Palabras de la Satiresa). La esfera es aquí un símbolo, más exacto si cabe, que el cisne; símbolo además de la unidad del universo. El arte no sólo es revelación de la belleza, es revelación también de la verdad y de la vida, pues las tres constituyen una indisoluble unidad: 
Vida, luz y verdad: tal triple llama

produce la interior llama infinita;

el arte puro, como Cristo, exclama:

ego sum lux et veritas et vita.

(Yo soy aquel que ayer nomás decia....

En CANTOS DE VIDA Y ESPERANZA).

Esta unidad del mundo a la luz de la belleza conduce, casi se diría lógicamente, a concebir la creación como una suprema obra de arte:

Y Palenque y la Atlántida no son más que momentos soberbios conque puntúa Dios los versos de su augusto poema.

(Salutación al Aguila, en EL CANTO ERRANTE).

Cada época literaria, cada escuela artística, elabora una imagen distinta del poeta; unas veces, como en el caso de Homero, es el cantor del héroe; otras, como en el falso pocma de Ossian, es el héroe mismo. En la Edad Media, el juglar anónimo encarna los deseos, las esperanzas populares y vive del recitado de sus poemas en plazas y castillos; en la corte barroca, el poeta fino y aristocráticicose deleitasen la creación de trasmundos artificiales y tiene pore bafdón "el aplauso de la plebe; a veces, el poeta es, o pretende ser, el guía, el conductor de su pueblo; en otras ocasiones, semejante al sabio taoísta, no debe adelantarse sino seguir al pueblo. Para el modernismo la función del poeta tiene un carácter sacerdotal y casi demiúrgico. "La celeste unidad que presupone hará brotar en ti mundos diversos" dice Rubén Darío en un soneto de Prosas Profanas (Ama tu ritmo); el poeta, semejante a un dios, tiene un poder sobrenatural que lo eleva por encima de los hombres; a los poetas se dirige Darío en un rapto lírico hermoso, entusiasta e intenso:

¡Torres de Dios! ¡Poetas!

Pararrayos celestes, que resistía las duras tempestades, como crestas escuetas, como picos agrestes, rompeolas de las eternidades!

( Torres de Dios! ¡Poetas!, CANTOS DE VIDA Y ESPERANZA). 
Es esta una concepción aristocrática del arte. Darío la repite en prosa concreta, de un modo directo, en su prefacio a Cantos de Vida y Esperanza: "Mi respeto por la aristocracia del pensamiento, por la nobleza del Arte, siempre es el mismo". Sin embargo, este aristocratismo no significa, como en el caso de Gónฐora por ijenıplo, el aislamiento del poeta; ni, por lc tanto, tiene como metá una poesía hermética, incomprensible para el vulgo. No es por azar ni por falta de gusto, que Darío no comprendiera cabalmente el valor de la poesia de Mallarmé, ni pretendiera imitarla. Los ideales estéticos de Mallarmé y Darío son distintos y sus coincidencias, casuales.

La aristocracia modernista no pretende una cerrada vida de invernadero. El mito de la torre de marfil no es típicamente modernista, como se suele creer comúnmente; no diremos que en su vida y en su obra el poeta modernista refleje totalmente el mundo que lo rodea, pero no fue un incomprendido ni lo persiguió la sociedad en que vivía; contó, más bien, con la admiración y el aplauso públicos y oficiales. El poeta modernista aspira, en el fondo, a ser un guía espiritual; por eso hay en la poesía de Darío un propésito permanente de claridad expresiva, lo que puede interpretarse propiamente como un deseo de alcanzar la comprensión umiversal. En su soneto, A los poetas risueños, dice Rubén Darío, hablando de Anacreonte, Banville, Ovidio y —extrañamente-Quevedo:
$\ldots$ prefiero vuestratioca de Letras sonora. vuestra musa risueña, vuestros versos perfumados de vino, a los versos de sombra y a la canción confusa que opone el numen bárbaro al resplandor latino.

(A los poetas risueños, PROSAS PROFANAS).

Este deseo de alcanzar la comprensión universal de la humanidad explica, en parte, el apartamiento modernista de las oscuridades del simbolismo. Pero no constituye, de ningún modo, una concesión a los gustos del vulgo. El idealismo rubendariano que imprime su carácter a la escuela modernista, es entero e incorruptible:

Alma mía perdura en tu idea divina;

todo está bajo el signo de un destino supremo;

sigue en tu rumbo, sigue hasta el ocaso extremo

por el camino que hacia la Esfinge te encamina.

(Alma mía, PROSAS PROFANAS). 
Este poema, Alma mía, acaba con unos versos altamente significativos: "atraviesa impertérrita por el bosque de males/ sin temer las serpientes, y sigue, como un dios..." Idealismo sin rendición ni concesiones, era natural que chocara con la realidad en torno. Muchos de los poemas últimos de Darío nos revelan el fracaso de sus ideales: Lo Fatal, A Phocás el campesino, A Colón, etc. Poemas melancólicos, resultado fatal de las tristes experiencias del poeta; sin embargo la explicaçión de su actitud pesimista ante la realidad no es, no puede ser, puramente sicológica:

Brumas septentrionales nos llenan de tristeza;

se mueren nuestras rosas, se agotan nuestras palmas; así no hay ilusiones para nuestras cabezas, y somos los mendigos de nuestras pobres almas.

(Los Cisnes, CANTOS DE VIDA Y ESPERANZA).

El idealismo de Rubén Darío no es una flor rara, singular, solitaria; a la luz del análisis aparece motivada por el mundo donde nació y vivió, por la sociedad que lo rodeaba. De hecho, aunque prefiriera los temas eróticos o amorosos, buena parte de su poesía tiene un hondô y amplio contenido social. Hay en la poesía de Darío unabpnofundal paesién americana: los paisajes y la historia, el pasado jeldfuturai yoelepresente de la "América ignota" aparecen reflejados en poemas admirables: Tutecotzimi, Momomombo, Canto a la Argentina son, acaso, algunos de los más notables. Pero Darío no se limita a cantar plácida y dulcemente, la vieja historia americana, ni su exuberante geografía; su ambición poética es mayor:

A través de las páginas fatales de la historia nuestra tierra está hecha de fervor y de gloria, nuestra tierra está hecha para la humanidad.

(Retorno, POEMA DEL OTONO).

La poesía de Rubén Darío nace y crece en una época importante de la historia latinoamericana; una época de optimismo que Darío recoge espléndida y brillantemente. En un momento en que la doctrina de Monroe ("América para los americanos") empieza a mostrar su verdadero carácter, su estrecho egoísmo nacionalista e imperialista. En ese momento, Darío proclama su ideal generoso y ecuménico: "América para la humanidad". La nota fundamental de este pensamiento america- 
nista es la esperanza; después de los turbulentos años que sucedieron a las guerras de la independencia, los países del nuevo continente parecen haber encontrado su destino, y se hacen lenguas de un halaguieño porvenir:

\author{
¡Gloria a América prepotente! \\ $\mathrm{Su}$ alto destino se siente \\ por la continental balanza \\ que tiene por fiel al istmo; \\ los dos platos del continente \\ ponen su caudal de esperanza \\ ante el gran Dios sobre el abismo.
}

(CANTO A LA ARGENTINA).

En Los Cisnes, poema citado más arriba, Darío llega a preguntarse desgarradoramente: " ¿Seremos entregados a los bárbaros fieros? ¿Tantos millones de hombres hablaremos inglés?". Y en el Prólogo del libro al que pertenecen estos versos - Cantos de Vida y Esperanza- dice claramente: "Mañana podremos ser yanquis ( $y$ es lo más probable); de todas maneras mi protesta queda escrita sobre las alas de los inmaculados cisnes, tan ilustres como Júpiter". La certera y penetrante visión de la realidad política que le tocó vivir, y de sus proyecciones futuras, aparece en varios poemihliqtecsứs tútrthos libros; acaso el más

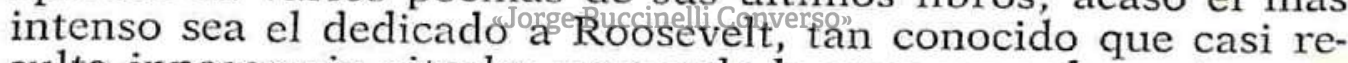
sulta innecesario citarlo; pero vale la pena recordar estos versos:

Eres los Estados Unidos, eres el futuro invasor

de la América ingenua que tiene sangre indígena, que aún reza a Jesucristo y aún habla en español.

(A Roosevelt, CANTOS DE VIDA Y ESPERANZA).

Versos lapidarios que resumen el pensamiento de Darío acerca de la política americana de su tiempo y nos muestran, además, contrariamente a lo que pensaba Rodó, la dimensión social de su poesía, de su espíritu.

Pero Rubén Darío no solamente comprendió certeramente las relaciones entre la América Latina y los Estados Unidos; percibió también el profundo malestar social interno de los países situados al sur de Río Grande y es entonces cuando su pe- 
simismo desborda el vaso de manera incontenible. En sus más dramáticos poemas de tema social y politico suele encontrarse al cabo una nota de esperanza: Los Cisnes, por ejemplo, termina así:

La aurora es inmortal. La aurora

es inmortal. $\mathrm{OOh}$ tierra de sol

y de armonía, aún guarda la Esperanza

la caja de Pandora!

\section{(Los Cisnes en CANTOS DE VIDA Y ESPERANZA).}

En contraste con estos versos, el poema A Colón, es totalmente desolado y sin esperanza; en él se describe la triste realidad social de América donde "las ambiciones pérfidas no tienen diques, soñadas libertades yacen desechas", donde fraternizan "los judas y los caínes" y donde gobiernan "las panteras engalonadas"; en el ápice de su pesimismo llega a exclamar desesperadamente:

1Pluguiera a Dios 1as aguasantes intactas

no reflejaran nuncá. las blancas velas;

ni vieran las estrellas estupefactas

arribar a la orillaitus canabelas'ás

"Jorge Puccinelli Converso"

(A Colón, en el CANTO ERRANTE).

Estos versos y muchos más - algunos de ellos mencionados anteriormente - nos revelan cómo Darío fue un poeta de su tiempo y de su patria, entendiendo por patría, según la frase precursora de la Independencia, "la vasta extensión de ambas Américas". Americano esencial, Rubén Darío respondió siempre a las necesidades y esperanzas de su tierra americana; sus versos melodiosos, aun los más personales y torremafileños, son el producto no sólo de un alma singular y grande sino también de una época y un continente.

Cualesquiera sea el juicio que merezca su poesia, el genio de Rubén Darío es indudable; nadie como él ha hecho sonar en el idioma castellano tan refinada música. "Hasta en los versos más épicos de Darío - ha dicho Jorge Basadre- hay un rumor de violines" y, comparándolo con otro gran poeta sonoro, aunque no precisamente melodioso, añade: "hasta en los versos 
más líricos de Chocano hay siempre un estrépito de banda". Las rimas, las alteraciones, las onomatopeyas, las combinaciones rítmicas de acentos, el timbre de las palabras, todos los recursos sonoros del idioma, los utiliza Darío de un modo magistral y delicado, maravilloso, sutil y original. Pero la sola genialidad individual no basta para explicar el valor ni el significado de su poesía; ni, por supuesto, su enorme resonancia en el continente americano, donde fue la cabeza indiscutible del movimiento modernista, escuela que juntó un numeroso contingente de poetas y prosistas notables. No existe, además, el genio químicamente puro y la frase de Wilde: "el genio es siempre solitario", nos parece totalmente falsa; Robinson Crusoe es una figura puramente imaginaria, incluso en el mundo del espíritu. El artista de genio encarna en su obra, de un modo u otro, la realidad humana de la comunidad en que vive; cuanto más amplia, en el espacio y en el tiempo, es su coincidencia con los ideales e intereses del mundo que lo rodea, mayor es su genialidad artística y la grandeza de şu obra. El mismo Darío lo comprende así: "He expresado lo expresable de mi alma - dice en el prólogo a $E l$ Canto Errante-, y he querido penetrar en el alma de los demás, y hundirme en la vasta alma umversal". Se puede afirmar, por estas razones, que la obra de Rubén Darío sólo puede ser comprendida cabalmente a la luz de la historia americana que le tocó vivir.

\section{Biblioteca de Letras}

¿Cuál es el sentidorgleulaihistoriaoamericana en la época modernista? ¿Qué relación vital y artística se establece entre el poeta Darío y su tierra americana? Estas son algunas preguntas que imprescindiblemente deben ser contestadas antes de emprender la crítica literaria justa de la poesía rubendariana. Es necesario comprender, en primer término, la historia americana del siglo XIX, describir sus líneas de fuerza, sus raíces en el pasado, sus proyecciones en el futuro. La América Hispana que durante tres siglos fue una colonia - varias, en realidad, pero la división obedece a razones puramente administrativas-, dependió política y económica y culturalmente de una metrópoli lejana, extracontinental. Eso explica, entre otras cosas, lo desvaído y desmedrado de su literatura, la "inteligencia" americana vegetaba de espaldas a su realidad, de espaldas a la tierra y el pueblo circundantes y con la mirada fija en la corte madrileña. La literatura colonial americana tiene un carácter exclusivamente imitativo; los poetas coloniales se dedicaron únicamente a seguir, ciega y mansamente, las modas literarias españolas: gongorizaban en la época de Góngora o se atenían a las normas neoclásicas bajo el dictado de Luzán; 
pero no traducían nada o casi nada de lo que pasaba bajo sus propias ventanas. Así como, por ejemplo, en el Perú se laboreaban las minas no por necesidades nacionales sino para atender a las exigencias de la metrópoli; así también, los poetas limeños escribían sus versos no para expresar los ideales ni lograr el aplauso del público peruano, los escribian al gusto y según la moda de la corte madrileña que, por lo demás, ningún caso hacía de ellos.

Políticamente, económicamente, culturalmente, América Latina vivió bajo el imperio de la monarquia española. Producida la independencia, se rompieron inmediata y totalmente los lazos económicos y políticos. En el ámbito cultural la historia es más complicada; en primer lugar, a las guerras de la independencia les sucedió un período de anarquía política, caos administrativo y postración económica, resultado lógico de los cuantiosos gastos de las campañas bélicas, de la poca preparación política de la nueva clase dirigente, de la necesidad de reestructurar una economía anquilosada en tres siglos de sometimiento a los intereses de la metrópoli, en tal situación era prácticamente imposible un desarrollo cultural apreciable. En segundo lugar, las vinculaciones culturales suelen ser más estrechas y profundas que las económicas o políticas; en algunos casos son irrompibles; el idioma, por ejemplo, el idioma oficial y hablado por la mayoríalideela qooblación continuó siendo, lógicamente, el castellano. meros años de vida independiente no tuvo mayor calidad que durante la colonia y continuó siendo un apéndice, en cierto modo superfluo, de la literatura española. Si a veces se nota, en ciertos escritores, influencia francesa o inglesa o italiana, el fenómeno se debe a la decadencia de la propia literatura española dedicada también a la imitación de las escuelas. de moda en el resto de Europa; pero hay que señalar todavía que la imitación americana de modelos europeos — franceses o ingleses, italianos o alemanes-suele hacerse de un modo indirecto: a través de las traducciones, versiones o imitaciones españolas.

Treinta o cuarenta años después de la independencia, la situación cambia y mejora ostensiblemente: se descubren y explotan productos de alto valor comercial y América Latina ingresa, digámoslo así, al mercado internacional como productor de materias primas. Económicamente, continúa en una situación dependiente, pero en condiciones más ventajosas que antaño: ya no está sometida rígidamente al monopolio comercial de una metrópoli ultramarina, ha pasado a depender de una entidad 
abstracta - el mercado internacional - lo que le permite gozar de una mayor flexibilidad contractual y obtener mayores ventajas pecuniarias. En esta época afluyen a la América Latina los capitales extranjeros; se "descubre" la extensión, riqueza y ferecidad de sus territorios; $y$, junto con los capitales, llegan también, de las regiones más pobladas del Viejo Mundo gran copia de inmigrantes. El signo de los tiempos puede ser la frase de Alberdi: "gobernar es poblar". El auge económico tuvo efectos políticos inmediatos: cesó la anarquía militar, se estabilizaron los gobiernos - generalmente civiles-, y se emprendieron obras públicas de gran aliento. Esta bonanza política y hacendaria dio lugar a un tipo de pensamiento optimista, a una ideología esperanzada. América Latina parecía haber encontrado su destino; parecía entrar - para decirlo con palabras actualesen la etapa del "despegue"; se creía que las riquzas disponibles eran - como su territorio- variadas, inmensas, inagotables; que si el presente se mostraba halagüeño el porvenir sería brillante y América se convertiría en el emporio de la humanidad. Junto a la riqueza material -0 , más propiamente, a causa de clla- hay en esta época el ansia secreta de crear una paralela riqueza espiritual. No se trata de un ideal explícito, pero así como América se cree llamada a convertirse en el emporio de la humanidad, asimismo se-siente en trance de crear una gran cultura. Las corrientes inmîgracionistas favorecen además la idea de que esta nuevabćul tuma debenser universal, y estar dirigida a los hombres de todascilals crazas, de todas las latitudes; de la misma manera que las tierras americanas esperan el trabajo de gentes venidas de todas las regiones del globo, la cultura americana se debe construir con el aporte de todos los pueblos, con la herencia de todas las épocas; abierta a las lecciones de la historia y a las inquietudes del presente, esta cultura estaba llamada a unir las más variadas esencias del ingenio humano en un solo haz universal.

En este momento nace Rubén Darío, esta es la savia nutricia de su poesía, y la explica en gran parte. Su cosmopolitismo que hemos analizado ya, está profunda y claramente emparentado con el "gobernar es poblar" de Juan Bautista Alberdi; el acopio de referencias culturales, múltiples y diversas que repleta su poesía corresponde a una concepción ecuménica de la cultura. El cosmopolitismo de Rubén Darío no se agota en las enumeraciones exóticas, en las reminiscencias de Grecia y Roma, de la España Morisca, de la América Indígena, del arte chinesco o versallesco, de los pasajes bíblicos y evangélicos o de las japonerías; su cosmopolitismo se nota también en la reunión 
de técnicas, motivos, temas y procedimientos poéticos de varias escuelas literarias del siglo XIX: el romanticismo, el parnasianismo, el simbolismo, el naturalismo; escuelas diversas, y en algún caso opuestas, cuya unión en la poesía rubendariana tiene un evidente propósito ecuménico, universalizador. Dificilmente se puede explicar de otro modo que una misma persona haya podido escribir, por ejemplo, un poema tan bellamente artificioso como Blasón y un cuento tan desgarradamente naturalista como El Fardo. "El verdadero artista - se lee en el prólogo a El canto errante- comprende todas las maneras y halla la belleza bajo todas las formas".

Quienes le reprochan a Dario su "incapacidad" para com. prender las más refinadas esencias del simbolismo francés olvidan que una poesía oscura y difícil, exclusiva y de jardín cerra. do, no tenía cabida en los ecuménicos ideales americanos de la época. En toda la poesía modernista se percibe un perenne afán de claridad expresiva; la poesía - para los modernistas- no sólo debe ser universal en sus fuentes, debe serlo también en sus proyecciones y dirigirse a un público plural que pueda gustarla, que pueda entenderla. En el prólogo a Cantos de vida $y$ esperanza, Darío lo dice sin ambages: "Yo no soy un poeta para las muchedumbres. Pero sé que infectiblemente tengo que ir a ellas". En estas frases están expresados dos grandes ideales modernistas cuya aparentescontradicción hemos explicado: el aristocratismo y el afán deruniveresadidadon

Motivación y propósitos semejantes a los del cosmopolitismo se encuentran en el idealismo de Rubén Darío. Este idealismo supone la existencia de unas ideas o valores perfectos. Todo el modernismo es la búsqueda o el canto de una belleza universal, eterna, intangible; el cisne, ave bella en sí misma es el emblema exacto de este ideal modernista. Toda la imaginería rubendariana, todo el caudal de ritmos, rimas, palabras y sonidos preciosos está dedicado a revelar esa belleza ideal. Hay quienes se sorprenden al encontrar en la poesía de Rubén Darío semejante lujo verbal, un empeño tan tenaz por encontrar vocablos refulgentes, cuando ya Mallarmé había proclamado que las palabras no tienen importancia en sí mismas, que su valor es funcional en el texto escrito, que es vano buscar el vocablo singular y brillante pues en el poema las palabras deben estar integradas "reflejándose unas en otras, hasta que no parezcan tener color propio sino ser transiciones en una escala". Son, como se ve, dos estéticas diferentes, por no decir opuestas. Rubén Darío busca una belleza universal y destellante; Mallar- 
mé una belleza íntima, casi intransferible. Aunque ocasionalmente Darío y Mallarmé vivieran en la misma ciudad, al mismo tiempo, pertenecen en realidad a dos épocas, a dos sociedades distintas. Hugo Friedrich ha señalado cómo el poeta europeo, a partir del romanticismo, se ha ido extrañando de su ambiente social; cómo, huérfano de protección oficial, falto de apoyo público, ha dejado de cumplir una función social y su poesía, abandonando todo propósito de comunicación amplia y abierta, se ha encerrado en un sistema expresivo hermético, resultado de una rebeldía personal, más o menos explícita. En la América Latina las cosas suceden de un modo semejante, pero no al mismo tiempo; la rebelión de los poetas y su extrañamiento social no se producen en el romanticismo del siglo XIX sino durante los movimientos de vanguardia de este siglo. Rubén Darío y los poetas modernistas, a pesar de las viscisitudes de la politica criolla, gozaron en general del apoyo de los gobiernos, y del aplauso y admiración de los públicos americanos.

La poesía de Rubén Dariolsurge en una época de optimismo y esperanza; una mirada perspicaz, sin embargo, podía descubrir el engaño y falsedad-escondidos tras esa actitud panglosiana. Uno de los méritos de Rubén Darío es haber tenido muchas veces esa mirada perspicaz. Poemas como Los Cisnes, A Roosevelt, A Colón, nos dap una imagen de Darío muy alejada de la torre de marfil a la qujlikedo parece confinarlo.

La estética de Rubén Darío puede haber periclitado; sus ideales no son ya los nuestros. Trágicamente la historia posterior ha demostrado en su propia obra, que la belleza no es eterna ni invariable, sino precedera y cambiante; muchos de sus poemas no son ya comprendidos y gustados. Pero su actitud personal, su indesmayable y sincera fe en la belleza, su profunda y vital vocación poética lo han convertido en el portavoz de su tiempo. Restaurador maravilloso de la maltrecha poesía española, artífice delicado de la música verbal — sin par en idioma castellano_, aristocrático soñador de mundos ideales, aunque toda la belleza de sus versos se derrumbe, Rubén Darío sobrevivirá porque fue un hombre que "expresó lo expresable de su alma, y quiso penentrar en el alma de los demás y hundirse en la vasta alma universal". Es decir fue un poeta en el más alto y generoso sentido de la palabra. 